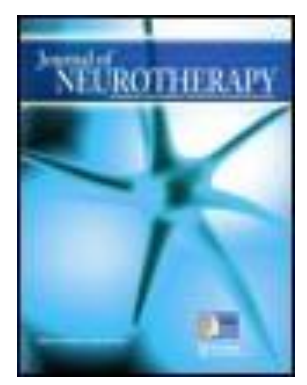

\author{
Journal of Neurotherapy: Investigations in \\ Neuromodulation, Neurofeedback and Applied \\ Neuroscience
}

\title{
Summaries and Abstracts of Scientific Papers Presented at the 2001 Society for Neuronal Regulation 9th Annual Conference, Monterey, CA
}

Published online: 08 Sep 2008.

To cite this article: (2002) Summaries and Abstracts of Scientific Papers Presented at the 2001 Society for Neuronal Regulation 9th Annual Conference, Monterey, CA, Journal of Neurotherapy: Investigations in Neuromodulation, Neurofeedback and Applied Neuroscience, 6:1, 39-43, DOI: 10.1300/J184v06n01_04

To link to this article: http://dx.doi.org/10.1300/J184v06n01_04

PLEASE SCROLL DOWN FOR ARTICLE

(C) International Society for Neurofeedback and Research (ISNR), all rights reserved. This article (the "Article") may be accessed online from ISNR at no charge. The Article may be viewed online, stored in electronic or physical form, or archived for research, teaching, and private study purposes. The Article may be archived in public libraries or university libraries at the direction of said public library or university library. Any other reproduction of the Article for redistribution, sale, resale, loan, sublicensing, systematic supply, or other distribution, including both physical and electronic reproduction for such purposes, is expressly forbidden. Preparing or reproducing derivative works of this article is expressly forbidden. ISNR makes no representation or warranty as to the accuracy or completeness of any content in the Article. From 1995 to 2013 the Journal of Neurotherapy was the official publication of ISNR (www. Isnr.org); on April 27, 2016 ISNR acquired the journal from Taylor \& Francis Group, LLC. In 2014, ISNR established its official open-access journal NeuroRegulation (ISSN: 2373-0587; www.neuroregulation.org).

THIS OPEN-ACCESS CONTENT MADE POSSIBLE BY THESE GENEROUS SPONSORS

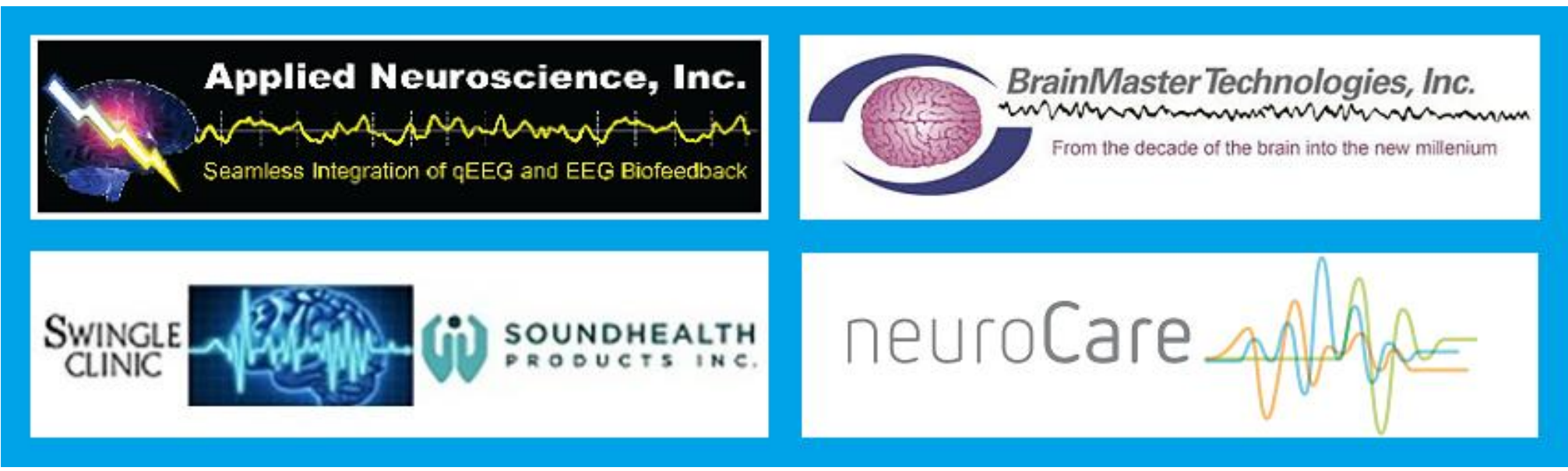




\section{Summaries and Abstracts of Scientific Papers Presented at the 2001 Society for Neuronal Regulation 9th Annual Conference, Monterey, CA}

(Presented alphabetically by senior author)

\section{CONTENTS}

Editorial Note: Introduction to Scientific Abstracts, SNR 2001

David L. Trudeau, MD

Task Related Slowing: Deactivation, or Cognitive Processing Deviation?

Efthymios Angelakis, MA and Joel F. Lubar, PhD

Premenstrual Dysphoric Disorder and Changes in Prefrontal Alpha Asymmetry

Elsa Baehr, PhD

Thinking Nonlinearly About Nonlinear Brain System Dynamics

Michael E. Brandt, PhD

The Mean of the Median: A New Metric for Targeting in Clinical Neurofeedback?

Valdeane W. Brown, PhD

Journal of Neurotherapy, Vol. 6(1) 2002

Copyright (C) 2002 ISNR. All rights reserved. 
AVS (Audio-Visual Stimulation) Effects in an Alzheimer's Patient as Documented by QEEG and LORETA

Thomas Budzynski, PhD and Leslie Sherlin, BA

Passive Infrared Hemoencephalography: A Three-Year Case Series Jeffrey A. Carmen, PhD

Intention and Consciousness in Neurofeedback

Thomas F. Collura, PhD

Logistic Regression Discriminant Functions for QEEG and LORETA Marco Congedo, MA and Joel Lubar, PhD

A Pre-Post Analysis of a Successfully Treated Case of Tourette's Syndrome

Raymond M. Daly, PhD

Comparison of Videogame \& Standard EEG Biofeedback with ADHD Children: Results of the First Concept Study

Roger J. deBeus, PhD, Olafur S. Palsson, PsyD, Alan T. Pope, PhD

John D. Ball, PhD and Marsha J. Turner, MA

QEEG-Based versus Research-Based EEG Biofeedback Treatment with Chemically Dependent Outpatients: Preliminary Results

Roger J. deBeus, PhD, Holly Prinzel, MS, Adrianne Ryder-Cook, LLD, and Lynn Allen, $R N$

QEEG Explorations of Childhood Expressive Dysprosody

John W. DeLuca, PhD and Ray Daly, PhD

Learned EEG Self-Regulation, Attentional Performance and Electrocortical Potentials in Healthy Subjects

Tobias Egner, BSc and John Gruzelier, PhD

Differences Between Coherence and Spectral Correlation During Auditory and Visual Stimulation at Dominant Alpha Frequency

Jon A. Frederick, PhD and Joel F. Lubar, PhD

Theta/Alpha Training in Application to Enhancement of Musical Performance

John Gruzelier, PhD and Tobias Egner, BSc 
Major Depressive Disorder: QEEG Based Subtypes and Treatment Implications

Robert L. Gurnee, MSW

The QEEG: Everything You Need to Know Is in the Waveforms

William J. Hudspeth, PhD

Relationship Between Epilepsy, ADD/ADHD, LD and Retardation

John R. Hughes, MD, PhD

Efficacy of Neurofeedback for Autistic Spectrum Disorders

Betty Jarusiewicz, PhD

Technology Overview: Bispectral Analysis

Jack Johnstone, PhD

Use of QEEG in Predicting Response to Medication

Jack Johnstone, PhD

Rethinking Standard Bands

David A. Kaiser, PhD

Audio Visual Entrainment and Neurofeedback

Sharon Koberna, MA and Brent Maguire, PhD

QEEG Findings Among Chronic Pain Patients with Suspected Mild TBI

Edward Kravitz, PhD, Mark Thimineur, MD, Mark Aron, PhD, and Annette Macannuco, MD

Event-Related Potentials in GO/NOGO Paradigm in ADHD Children During EEG-Based Biofeedback Training

Juri D. Kropotov, PhD

Effects of a Pulsed Electromagnetic Therapy on Migraine Headaches

Martha S. Lappin, PhD and Fraser Wilson Lawrie, MS

Pills, Politics and Placebos Revisited

T. J. La Vaque, PhD 
Anterior Alpha Asymmetry in Depression

Robert Lawson, MS and Eugenia Bodenhamer-Davis, PhD

Correlations Between Version 2 and Version 3 of the Lifespan Database, and Comparison of the NYU and Thatcher MTBI Discriminants Robert Lawson, MS, Richard Herrington, PhD, William Hudspeth, $P h D$, and Marvin Sams, ND

Quantitative EEG Normative Databases: A Comparative Investigation.

Tamara D. Lorensen, BSc Grad Dip and Paul Dickson, BSocSci, BPsych

Neurocardiac Dynamics: The Relationship Between Heart Rhythm Coherence, Heart-Brain Synchronization and Cognitive Performance

Rollin McCraty, PhD

Malingering Indicators on the Conners' CPT II

J. Trevor Milliron, PhD

Neurofeedback for the Bipolar Child

Siegfried Othmer, PhD

Neurophysiology and Non-Linear Dynamics of Object Perception Karl Pribram, MD

Effects of HEG Training at Three Prefrontal Locations Upon EEG Ratios at $\mathbf{C Z}$

Robert Sherrill, Jr., PhD

EEG Changes on TBI Patients During Cognitive Tasks After Cognitive Rehabilitation

Stamatina Stathopoulou, MA and Joel F. Lubar, PhD

QEEG-Guided Neurofeedback in the Treatment of Epilepsy: An Up-Date for the New Millennium

M. Barry Sterman, PhD

QEEG and Traumatic Brain Injury: A qEEG and qMRI Synthesis R. W. Thatcher, PhD, Carl J. Biver, PhD, Rebecca A. Walker, BS, and Duane North, MA 
Combined Neurofeedback and Biofeedback for Dystonia and Parkinson's Disease: Theory and Case in Progress

Michael Thompson, MD and Lynda Thompson, PhD

Task-Related EEG Alpha Desynchronization During a Cognitive Flexibility Task in Good versus Poor Performers

Edwin Verstraeten, MA and Raymond Cluydts, PhD

QEEG Reference Database Evaluation of Adult ADHD

J. Noland White, PhD and Joel F. Lubar, PhD

\section{POSTER PRESENTATIONS}

Relationships Between Eyes-Closed and Eyes-Open QEEG Parameters: Implications for Neurotherapy Treatment

Roger J. deBeus, PhD and Holly Prinzel, MS

QEEG and MMPI-2 Characteristics of a Sample of 12 Persons with Childhood Sexual Abuse

Lisa M. Black, MS, Alicia L. Townsend, BA, and Eugenia M.

Bodenhamer-Davis, PhD

Medical Study and Aid in Central Asia

Robert J. Hamilton

Neurofeedback Enhanced by Light Closed Loop EEG and Electromagnetic Closed Loop EEG in a Case of Sleep Deprivation Post Methadone Withdrawal

Victoria L. Ibric, MD, PhD 